\title{
Document Delivery at the International School for Advanced Studies Library of Trieste 1992-1995
}

\section{Lucio Lubiana}

During the period 1992-1995 the library of the International School for Advanced Studies of Trieste (Italy) increased the number of delivery transactions of journal articles with Italian university libraries and with the British Library Document Supply Center. Of these, two-thirds were requested by users in the biophysics sector and the rest by users belonging to the mathematics and physics sectors of ISAS. In the same period the ISAS library fell into the category of "npplicant library" rather than "provider library." An increase in requests for photocopied articles has been caused by the introduction of the Medline CD-ROM in the ISAS library and by the enlargement of the biophysics sector of the school. The purpose of this study is to find alternative ways of providing information to internal users in the face of decreasing budgets.

Tr Studies (ISAS), founded in 1978, is an international postgraduate school in physics, mathematics, biophysics, and neurosciences that promotes scientific research and prepares young graduate students from Italy and abroad for advanced research. It is located in Trieste, in northeast Italy, near the border with Slovenia. The ISAS has a small library that holds about 11,000 books and subscribes to five CD-ROM databases (including Medline) and 400 current journals. The library specializes in mathematics, physics, astronomy, and biophysics literature. It is being automated with Tinlib (IME, London) running on a UNIX platform; this system allows eight users simultaneous access to the system.

Both the ISAS library and the neighboring library of the International Center for Theoretical Physics (ICTP) of Trieste have a large collection of mathematics and physics journals. But their journal collections are insufficient for users in the biophysics sector of the school. In fact, the number of requests for journal articles sent by the ISAS library to other libraries has grown from 60 in 1992 to 323 in 1995, of which two-thirds were requested by students in the biophysics sector (see table 1). 
TABLE 1

Total Number of Journal ARticles Requested by All USERs of the School

\begin{tabular}{lcccccr}
\hline \hline Year & No. Requests & $\begin{array}{c}\text { No. Articles } \\
\text { Found in Italy }\end{array}$ & $\begin{array}{c}\text { No. Articles } \\
\text { Found in } \\
\text { BLDSC }\end{array}$ & $\begin{array}{c}\text { No. Articles } \\
\text { Found in Other } \\
\text { Countries }\end{array}$ & $\begin{array}{c}\text { No. Requests } \\
\text { Cancelled }\end{array}$ & $\begin{array}{c}\text { No. } \\
\text { Requests } \\
\text { Fulfilled }\end{array}$ \\
\hline 1992 & 60 & 60 & - & - & - & 60 \\
1993 & 164 & 152 & 15 & - & - & 164 \\
1994 & 230 & 214 & 15 & 1 & 8 & 222 \\
1995 & 332 & 290 & 41 & 1 & 4 & 328 \\
\hline
\end{tabular}

With the growth of the biophysics sector at the beginning of 1990 , the library's journal collection was enlarged-but not enough to satisfy all of the information needs of these users. For this reason, the library decided to open a delivery service and interlibrary loan for internal users (Comba 1994; Pedersen and Gregory 1994; Alpigiani and Grilli 1994; Ferguson and Price 1995; Holt and Schmidt 1995; and Kohl 1995). This was done in 1992 and expanded during 1993.

One of the principal bibliographic tools for locating journals in Italian libraries is the Catalogo collettivo nazionale delle pubblicazioni periodiche CNR, a union list of journals of Italian libraries (ISRDS 1990). This is the only bibliographic tool covering nearly all the university libraries of the country. The university libraries of Trieste, Udine, Padova, and the ISAS are not included in this union list. Recently this union catalog became accessible online through the GARR network (universities network of Italy) located at the University of Bologna (http://www.cib.unibo.it). In 1994 the catalog became available on CD-ROM. The ISAS library is still using this bibliographic tool for locating journals in Italian libraries.

Another bibliographic source, even if not up to date, for locating journals in the northern part of Italy is the union list of periodicals of the libraries of Lombardia (Catalogo dei periodici correnti delle biblioteche lombarde 1985-1991). To verify journal citations, the library also uses Gale's Periodical Title Abbreviations (1992) and Ulrich's International Periodicals Directory (1991). Italy does not have a public or private centralized library provider of documents like the British Library Document Supply Center (BLDSC). This lack of a centralized and efficient delivery service is particularly evident in medical sciences and pharmaceutics. For this reason a group of medical libraries in central and northern Italy decided in 1983-1984 to found the Italian Association of Documentation for Biomedical Research and the Pharmaceutical Industry (GIDIF-RBM, Gruppo Italiano Documentalisti Industrie Farmaceutiche e Ricerca Bio-medica). Today this association is located in Milan with about forty associate libraries (public, private, pharmaceutical industries, and hospitals) whose aim is to keep the union catalog of journals up to date and to circulate photocopy requests free of charge among its members. This union catalog, containing about 4,000 current titles of periodicals, is available only to its associates both in print and online (Pesenti 1995). This example was not followed by other libraries in other fields of the sciences.

For mathematical sciences, a union list of periodicals owned by mathematics libraries of Italian universities was created. This project was undertaken in 1979 and 1988 by the Istituto per le Applicazioni del Calcolo (IAC) "Mauro Picone" of the Italian National Research Council (CNR) and has been continued by the University of Lecce. In 1991 the University of Lecce became the center of the national informative system for mathematics (SINM, Sistema Informativo Nazionale per la Matematica), which will provide for, among other things, the creation of an 
TABLE 2

NuMBER OF REQUESTS OF BIOPHYSICS USERS OF THE SCHOOL

\begin{tabular}{lccc}
\hline Year & $\begin{array}{c}\text { No } \\
\text { Rerjuests }\end{array}$ & $\begin{array}{c}\text { No. Articles Requested } \\
\text { in Italy }\end{array}$ & $\begin{array}{c}\text { No. Articles Requested } \\
\text { from BLDSC }\end{array}$ \\
\hline 1992 & 31 & 31 & - \\
1993 & 160 & 148 & 12 \\
1994 & 206 & 194 & 13 \\
1995 & 242 & 201 & 41 \\
\hline
\end{tabular}

efficient public national delivery service between mathematical libraries of Italy.

Within SINM, the University of Lecce, in accordance with CNR, is coordinating the growth of the union list of mathematical periodicals and is including in the CNR union list the mathematical periodicals of the IAC "Mauro Picone" (Istituto per le Applicazioni del Calcolo "Mauro Piccone" 1988). Also, the libraries of the Astronomical Observatories of Italy are building up a national bibliographic information system in astrophysics, developing a national union list of periodicals owned by astronomy libraries, and creating an efficient national delivery service. This project, called the union catalog of the Italian astronomical libraries (CUBAI, Catalogo Unico delle Biblioteche Astronomiche Italiane, http://www.oat.ts. astro.it/biblio/cubai.html), has among its goals that of creating an efficient and fast delivery service among the Italian astronomical institutes (Ferrucci 1995). These projects will be superseded by the creation, in the near future, of the national bibliographic service (SBN, Servizio Bibliotecario Nazionale), which will provide for, among other things, the creation of an efficient public national delivery service.

\section{BIOPHYSICS SECTOR OF THE SCHOOL}

This is the main sector of the school that depends on photocopied articles. In this highly specialized field of science it is essential that researchers be kept up to date with information that could affect their current work. The amount of scientific information in this field is growing so rapidly that no library can collect all of it. The collection of biophysics journals in ISAS library is not wide enough to satisfy all the information needs of scientists in this field.

One source for informing biophysics students of current bibliographic information is Current Contents-Life Sciences (available on computer starting from 1993), produced by the Institute for Scientific Information (ISI) of Philadelphia. This provides access to the tables of contents and bibliographic data from current issues of the world's leading journals in life science. But this source did not increase the number of photocopy requests at the ISAS library. The growth of requests for articles was noticed when Medline on CD-ROM was introduced in the library.

Medline has increased bibliographic access to information and pressure for physical access to information. For this reason the ISAS library had extended the collection of biophysical journals, but not so wide as to fulfill all of the information needs of these users. To meet the increasing requests of these users, the ISAS library decided to increase the document delivery service for internal users (Alston and Coomb 1992; Fox and Lancaster 1994). When Medline was introduced in 1992 , the photocopying requests of biophysics users numbered only 31 . In 1993 , when biophysics students had become much more knowledgeable about Medline, photocopy requests grew to 160 . During 1994, they grew to 206, and in 1995 this total increased to 242 (see table 2). At the time we noted that there seemed to be a close link between the use of Medline and the photocopy requests of journal articles. 
We have allowed internal users to use Medline themselves to locate articles unavailable locally so that they can request delivery at the library office. In fact, photocopy requests of articles were often made on the same day on which Medline was consulted. We verified this when users sent their requests to the library, writing the bibliographic citation from which the information was taken on opposite forms. More than $50 \%$ of these requests arose from consultation with Medline.

We also noticed that most of the documents requested were published in journals between 1987 and 1994. For users in this field of research, it is extremely important to obtain an article as soon as possible. In order to check article citations and their locations, the ISAS library uses the following bibliographic tools:

- CNR union catalog,

- Regional union list of medical periodicals,

- Biblioteche a Trieste, the catalog of periodicals at the Library of Medicine of the University of Trieste,

- Ulrich's Periodical Directory, and

- Periodical Title Abbreviations.

At the same time, the ISAS library bought journal catalogs of the principal Italian biomedical library and the catalogs of the University of Trieste and Udine. This was done mainly to locate journals in the neighboring libraries of the ICTP and the University of Trieste.

But the only library in Trieste that has an efficent document delivery service is that of the central Library of Medicine of the University of Trieste. For this reason we started requesting articles from this library, which provides articles from an in-house collection of approximately 1,000 current subscription titles and from the biomedical institutes of the University of Trieste and other universities (Biblioteca centrale di Medicina Università di Trieste 1990). The delivery service of the Trieste Library of Medicine is efficient, and requests are filled within one or two days if the journal is owned by the main library or within a week if it is owned by another library of the university.

All requests are sent to this library by fax on a ready-made form indicating, in capital letters, the title of the journal, year, volume, issue, pages requested, authors, and the indication of the university institute where the journal is located. The articles and invoices are delivered once a week by ISAS drivers. If the journals are not found in the libraries of Trieste or in the province, then they are located and ordered from other Italian libraries through the CNR union catalog. If none of these libraries owns the journals requested, then requests are forwarded to the British Library Document Supply Center. Normally all requests are made by fax, phone, or e-mail.

\section{MATHEMATICS SECTOR AND OTHER SECTORS}

The principal bibliographic tool for locating mathematical journals in Italian libraries is the Union Catalog of Scientific and Technical Periodicals, first published in 1979 under the title Catalogo collettivo dei periodici scientifici e tecnici. The second edition of this publication was published in 1981; the third, in 1988. This union catalog is available through the Italian network GARR at the University of Lecce (gopher/server SIBAl.Unile.it or 193.204.64.176 with login: “dsm") (Basile and Pettinati 1994).

Unlike users in biophysics, mathematics users adopted a different bibliographic search linked more to books than to journals or preprint. In fact, the number of requests for articles in the mathematics sector was lower than that for the biophysics sector. Over a period of three years, mathematics users, unlike those of biophysics, requested more articles with earlier dates. The articles requested were found in the neighboring libraries of the mathematics department of the University of Trieste and of the International Centre for Theoretical Physics (ICTP) of Trieste.

But the principal provider of photocopied articles for mathematics students during 1992-1995 was the mathematics department library of the University of Trieste. In fact, this library has the most complete collection of mathematical jour- 
nals written in English and German in northeastern Italy.

In 1992 the mathematics sector of the school requested 10 articles, while in 1993 only 4 requests were made. In 1994, 21 documents were requested by the mathematics sector of which only three were not found in Italy and were requested from the BLDSC. In 1995 mathematics users requested 15 journal articles, all of which were found in Italian mathematical libraries.

Astrophysics users did not request journal articles during 1992-1994. In 1995 astrophysics users requested 13 journal articles, of which all were found in the library of the Astrophysics Observatory of Trieste, which has the most complete collection of astrophysics journals in northeastern Italy. The physics users of the school have access to a wide range of information sources available inside the school and on network servers over the Internet (among them the Babbage preprint server, the Los Alamos preprint serv$\mathrm{er}$, and the SLAC (Stanford Linear Acceleration Center) preprint server at Stanford University, all of which also provide document delivery). It is perhaps for this reason that users requested only a small number of journal articles during 1994 (2 documents) and 1995 (2 documents).

In the fields of physics and astronomy, the American Institute of Physics (AIP) has developed the physics information network called Searchable Physics Information Notices (SPIN), which covers every major area of physics research (database, journals, abstracts, conference proceedings, preprints, and electronic bulletin boards). In addition, the new document delivery service Articles in Physics provides full-text copies of journal articles, proceedings, journal issues, and other AIP publications (Anderson and Pausch 1991, Albrecht and Egret 1991, Judd and Perugini 1994, Elxis 1995, Heck and Murtagh 1993, and Ricart 1995).

No one in the neuroscience sector of the school used the delivery service for requesting documents unavailable in the ISAS library. This sector is relatively new (Fox and Lancaster 1994).

\section{British Library Document SUPPLy Center (BLDSC)}

Photocopy requests for articles were sent to the BLDSC only when the requested journals were not found in an Italian library. BLDSC was chosen due primarily to the lack of a skilled Italian supplier of scientific documents, and also due to BLDSC's strong experience in the document delivery field. The relationship with this document supplier started in 1993, when the number of documents requested by internal users increased. From this point on the relationship with BLDSC was clear and no problems arose.

At first it was thought that the best way of paying BLDSC would be to purchase coupons through the British Council. But this idea was dropped, and in 1994 a deposit account was opened by which the ISAS library paid in advance for delivery requests. This method of payment was the best choice for both parties.

In 1993 and 1994, 15 photocopy requests were made to BLDSC; of these, only 2 were made by mathematics users and 1 by a physics student.

During these years all photocopy requests were mailed using a ready-made form supplied by BLDSC, on which were indicated the title of the journal, year of publication, volume, issue, page, authors, source of information from which it was taken, and BLDSC's coupons. In 1995 the method of request was changed, and in 1995 all requests were sent through electronic mail using BLDSC's ERTEmail system. In 1995 we requested 41 joumal articles, all of which were made by biophysics users of the school. All documents were sent to the ISAS library from England by mail, and all requests were fulfilled within a period of one or two weeks Along with the articles, the BLDSC also sent the certificate of clearance of copyright.

\section{Private Libraries}

Private libraries were contacted only when the journal was not found in public libraries. The requests were made by telephone or fax. In 1992 the ISAS library 
requested only 3 articles from 3 Italian private libraries. During 1993, 12 requests were sent to private libraries in the pharmaceutical industry and one to a hospital library (Hospital S. Raffaele Milano); all were fulfilled free of charge.

In 1994, 9 requests for articles were sent to 7 different Italian private libraries: Carlo Erba of Milano, Glaxo of Verona, Fidia of Abano Terme (Padova), library of the International Centre of Genetic Engineering and Biotechnology (ICGEB) of Trieste, and the library of the $S$. Raffaele Hospital of Milan.

In 1995, only 2 requests for documents were sent by the ISAS library to the followinglibraries: Fidia of Abano Terme (Padova) and Smithkline Beecham of Milano.

Most articles were delivered by mail within one week of the requests. During 1993-1995, the photocopy requests to private libraries were also free of charge. None of the Italian private libraries requested that the ISAS library observe the regulations of the Italian Copyright Act 1941.

\section{Costs and Method of Delivery}

All documents ordered and all delivery costs during the period 1992-1995 were paid for by the ISAS library. Requests for documents made to ISAS from internal users were received in the traditional way from 1992 to 1995 via written applications or telephone calls. To expedite this process, in 1994 the ISAS library developed a special order form for delivery service on paper that was distributed to internal users. Users requesting documents filled in the following information: user name, article title, journal title, year of publication, volume, authors, and journal issue.

Prior to 1994, the library did not receive requests for documents from internal users via e-mail. Starting in 1995, the library began to receive photocopy requests through e-mail, which will make possible the expansion of electronic document delivery. This project is still being tested.

All delivery transactions with other libraries were conducted via fax, mail, telephone, or e-mail. Documents were deliv- ered within 12 hours of receipt of the request. The most urgent requests were filled within one hour via fax. But the cost of delivering articles via fax is much higher than by ordinary mail. Most university libraries in Italy supply documents and exhange bibliographic information free of charge between peer institutions.

The principal provider of documents to the ISAS library was the central library of medicine of the University of Trieste, which charged the ISAS library for document delivery. The other libraries, with the exception of the library of Centro Regionale Oncologico of Aviano (Pordenone), the library of the Department of Pharmacology of the University of Milano, and one insitute of the University of Florence, did not charge for photocopied articles.

None of the Italian libraries requested verification that the ISAS was in conformance with the Italian Copyright Act 1941 before supplying an article. This was done only by the hospital library of the Centro Regionale Oncologico of Aviano (Pordenone), which put a copyright release statement on the first page of all articles provided: "a copy of the document is required for the purpose of research or study and in accordance with the Copyright Act 1941."

All Italian public and private libraries outside Trieste sent documents to ISAS using ordinary mail, and the delivery times were different between cities, ranging from two to three weeks from the date of request. During 1995 very urgent requests were sent via e-mail or fax. One document was received via e-mail from the Slovak republic in PostScript format, and the document was printed in the ISAS library.

\section{Conclusion}

To improve the sources of information for ISAS's users, it will be necessary to integrate delivery service into the automated system of the library, which will allow users to send and receive documents more easily and quickly. If in the future the number of requests for photocopied journals articles continues to increase, and if 
the ISAS library will have to eliminate more journal subscriptions, then the school should consider the possibility of automating this service and linking it to commercial suppliers for full-text article delivery.

These suppliers allow libraries to adopt more cost-efficient serials strategies, to enhance the automation of delivery service, and to establish user-mediated document delivery service ordering (Jackson 1993, Hugenholtz 1994, Capelli 1994, Revelli 1994, Carotti 1994, and Boretti 1995). Finally, the electronic retrieval and network delivery of Internet resources will change the way information will be delivered to end users.

Another goal of the library is to merge the delivery service into the daily reference work of the ISAS library, making use of electronic resources as a regular part of reference service. But the Italian situation in delivery service has remained behind that of the European market, with delivery methods slower than those of other European countries. In Italy we do not have a clear law on copyright, and royalties on photocopied articles in journals normally are not required. The Italian Copyright Act of 1941 must be changed, and a new copyright bill must be passed that will also consider the question of ownership of documents posted on the Intemet. This situation must change in order for Italy to catch up with the European market.

\section{WORKS CITED}

Alexis, D. 1995. More product information by Telnet and the World Wide Web. Computers in physics 9, no. 2: 138-39.

Alpigiani, C., and A. Grilli. 1994. Dal presitito interbibliotecario alla fornitura di documenti. Bollettino AIB 34, no, 2: 163-70.

Alston Y., and J. Coomb. 1992. Biosciences. New York: Stockton Pr.

Basile, C., and C. Pettenati. 1994. La biblioteca virtuale. Milano: Editrice Bibliografica.

Biblioteca centrale di medicina di Trieste. 1996. Catalogo dei periodici delle biblioteche biomediche di Trieste. Trieste: Biblioteca centrale di Medicina.

Biblioteche a Trieste. 1993. Lista dei periodici. Trieste: AIB.
Boretti, Elena. 1995. Dal divieto al servizio. Biblioteche oggi 13: 72-74.

Carotti, Carlo. 1994 Innovazioni? Sí ma virtuali. Giomale della libraria 108: 24.

Catalogo collettivo dei periodici dell' Università degli Studi di Udine. 1989. Firenze: Leo Olschki.

Catalogo dei periodici correnti delle biblioteche lombarde. 1985-1991. Milano: Editrice Bibliografica.

Catalogo regionale dei periodici di biochimica, farmacologia, medicina. 1990. Trieste: Area per la Ricerca Scientifica e Tecnologica di Trieste.

Comba, Valentina. 1994. Il servizio di document delivery e le biblioteche. Bollettino AIB 34, no. 2: 201-6.

Databases and online data in astronomy. 1991. M. A Albrecht and D. Egret, eds. Dordrecht: Kluwer.

Ferguson, A., and M. Price 1995. Document delivery: Staffing, technology, and budgeting implications. The serials librarian 25: $319-25$.

Ferrucei, Marco. 1995. CUBAI : Un sistema informativo bibliografico nazionale per l'astronomia, Bollettino AIB 35, no. 3:38186.

Fox, Peter T., and Jack L. Lancaster. 1994. Neuroscience on the Net. Science 266: 994-96.

A guide to library service in mathematics. 1993. Nancy D. Anderson and Lois D. Pausch, eds. London: JAI Pr.

Holt, J, and Karen A. Schmidt. 1995. CARL UnCover or Faxon Finder? Library resources d technical services 39: 221-28.

Hugenholtz, P. G. 1994. Copyright and electronic document delivery services. Interlending and document supply 22, no. 3 : 8-14.

Intelligent information retrieval. 1993. André Heck and F. Murtaugh, eds. Dordrecht: Kluwer.

Istituto per le Applicazioni del Calcolo (IAC) "Mauro Piccone." 1988. Catalogo collettivo dei periodici scientifici e tecnici. Istituti e dipartimenti matematici universitari. Istituti matematici del C.N.R., $3 \mathrm{~d}$ ed. Roma: C.N.R.

Istituto di Studi sulla Ricerca e Documentazione Scientifica (ISRDS). 1990. Catalogo collettivo nazionale delle pubblicazioni periodiche CNR. Roma: ISRDS.

Istituto Superiore di Santinà. 1990. Catalogo dei periodici indicizzati nel Medlars presenti nelle biblioteche biomediche italiane. Roma: Istituto Superiore di Santinà 
Jackson, Mary F. 1993. Document delivery over the Internet. Online 17, no. 2: 14-21.

Kohl, David F. 1995. Revealing UnCover. Online 52: 52-60.

Pedersen, W., and David Gregory. 1994. Interlibrary loan and commercial document supply. Journal of academic librarianship 20, nos 5/6: 263-72.

Periodical title abbreviations. 1992. Leland G. Alkire, ed. Detroit: Gale.

Pesenti, M. 1995. La gestione economica di un centro di informazione. Biblioteche oggi 13 , no. 6: 82-84.

Presitito Interbibliotecario: modalità di trasmissione dei documenti e recupero spese. 1995. SBN Notizie nos. 1/2: 27-29.

Revelli, Carlo. 1994. Pareri contrastanti sulle fotocopie. Biblioteche oggi 12: 46-51.
Ricart, G. 1995. The scholarly information Web. Computers in physics 9, no. 4: 360-63.

Rollins, Stephen J. 1986. Document delivery. In Scientific and technical libraries. Orlando: Academic Press, 205-30.

Sistema Informativo Nazionale per la Matematica. 1992. Atti del Seminario. Lecce: Università di Lecce.

Ulrich's international periodicals directory: The serials directory. 1991. Birmingham, Ala.: EBSCO.

Università degli Studi di Trieste. Biblioteca generale. 1992. Catalogo dei periodici correnti (al 9/10/92). Trieste: Università di Trieste.

Waldrop, Mitchell M. 1995. On-line archives let biologists interrogate the genome. Science 269: 1.356-58.

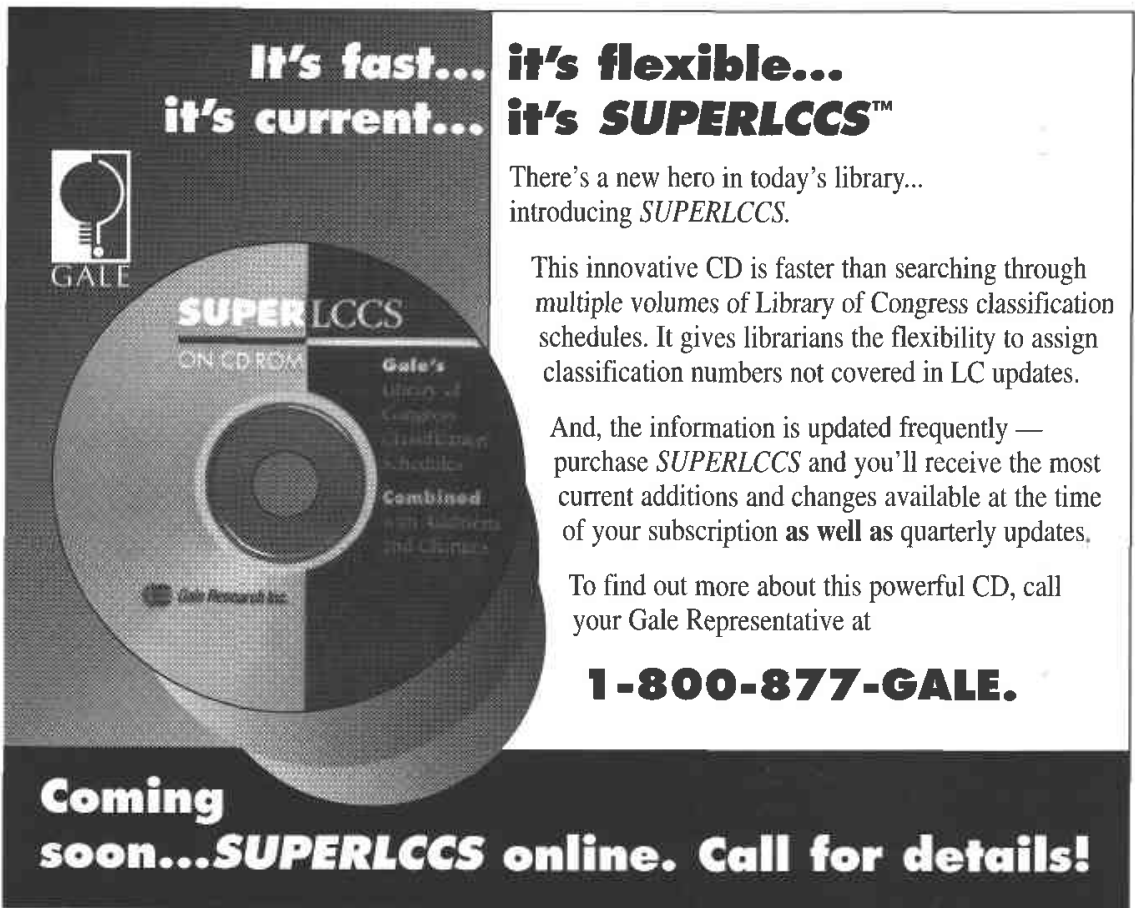

